\title{
Whole body composition analysis by the BodPod air-displacement plethysmography method in children with phenylketonuria shows a higher body fat percentage
}

\author{
Monique Albersen • Marjolein Bonthuis • Nicole M. de Roos • \\ Dorine A. M. van den Hurk • Ems Carbasius Weber • Margriet M. W. B. Hendriks • \\ Monique G. M. de Sain-van der Velden • Tom J. de Koning • Gepke Visser
}

Received: 20 December 2009/Revised: 17 May 2010 /Accepted: 25 May 2010/Published online: 24 June 2010

(C) The Author(s) 2010. This article is published with open access at Springerlink.com

\begin{abstract}
Background Phenylketonuria (PKU) causes irreversible central nervous system damage unless a phenylalanine (PHE) restricted diet with amino acid supplementation is maintained. To prevent growth retardation, a protein/amino acid intake beyond the recommended dietary protein allowance is mandatory. However, data regarding disease and/or diet related changes in body composition are inconclusive and retarded growth and/or adiposity is still reported. The BodPod whole body air-displacement plethysmography method is a fast, safe and accurate technique to measure body composition.
\end{abstract}

Communicated by: John H. Walter

Competing interest: All authors confirm that they have no competing interests for declaration.

M. Albersen · M. M. W. B. Hendriks •

M. G. M. de Sain-van der Velden • T. J. de Koning •

G. Visser $(\bowtie)$

Department of Metabolic and Endocrine Diseases,

Wilhelmina Children's Hospital, University Medical Centre Utrecht,

Huispost KC02.069.1, Lundlaan 6,

3584 EA Utrecht, The Netherlands

e-mail: G.Visser-4@umcutrecht.nl

M. Bonthuis

Division of Human Nutrition,

Wageningen University and Research Centre,

Wageningen, The Netherlands

N. M. de Roos

Department of Dietetics and Nutritional Sciences,

Julius Centre for Health Sciences and Primary Care,

University Medical Centre Utrecht,

Utrecht, The Netherlands

D. A. M. van den Hurk - E. Carbasius Weber

Department of Dietetics and Nutritional Sciences,

University Medical Centre Utrecht,

Utrecht, The Netherlands
Aim To gain more insight into the body composition of children with PKU.

Methods Patients diagnosed with PKU born between 1991 and 2001 were included. Patients were identified by neonatal screening and treated in our centre. Body composition was measured using the BodPod system (Life Measurement Incorporation ()$_{)}$. Blood PHE values determined every 13 months in the year preceding BodPod analysis were collected. Patients were matched for gender and age with data of healthy control subjects. Independent samples $t$ tests, Mann-Whitney and linear regression were used for statistical analysis.

Results The mean body fat percentage in patients with PKU $(n=20)$ was significantly higher compared to healthy controls $(n=20)(25.2 \%$ vs $18.4 \% ; p=0.002)$, especially in girls above 11 years of age $(30.1 \%$ vs $21.5 \% ; p=0.027)$. Body fat percentage increased with rising body weight in patients with PKU only $(R=0.693, p=0.001)$, but did not correlate with mean blood PHE level $(R=0.079, p=0.740)$. Conclusion Our data show a higher body fat percentage in patients with PKU, especially in girls above 11 years of age.

$\begin{array}{ll}\text { Abbreviations } \\ \text { PKU } & \text { Phenylketonuria } \\ \text { PHE } & \text { Phenylalanine } \\ \text { BH4 } & \text { Tetrahydrobiopterin } \\ \text { RDA } & \text { Recommended dietary allowance } \\ \text { BMI } & \text { Body mass index } \\ \text { CI } & \text { Confidence interval }\end{array}$

\section{Introduction}

Phenylketonuria (PKU, OMIM 261600) is an autosomal recessive inborn error of phenylalanine (PHE) metabolism, 
caused by a deficient function of phenylalanine hydroxylase (EC 1.14.16.1), which converts PHE to tyrosine (Walter et al 2006). Untreated, accumulation of PHE occurs and patients develop irreversible central nervous system damage. Treatment consists of a dietary restriction of PHE (Walter et al 2006). In addition, some patients may profit from tetrahydrobiopterin (BH4) supplementation (Blau and Erlandsen 2004). A normal intellectual development is expected when adequate treatment is started early in life and continued during life (DeRoche and Welsh 2008; Walter et al 2006).

The PKU diet comprises a restriction of natural protein and supplementation of essential amino acids with a PHE free amino acid mixture (Walter et al 2006). In the last century, patients on this diet often developed growth retardation (Allen et al 1996; Verkerk et al 1994). Therefore, nowadays, a total protein/amino acid intake exceeding the recommended dietary allowance (RDA) is advised (Acosta et al 2003). However, data regarding disease and/or diet related changes in growth and body composition are inconclusive and retarded growth is still being reported, mainly during the first years of life (Arnold et al 2002; Dobbelaere et al 2003). In addition, McBurnie et al (1991) showed higher body weights in prepubertal (age 2-10 years) children with PKU when compared to healthy control subjects, starting after 3 years of age and being positively related to serum PHE level. This effect was especially seen in girls. Furthermore, Walter et al (2002) reported blood PHE levels near or above the recommended upper limits, mainly among adolescents and young adults (age $\geq 10$ years) compared to younger children (age $<$ 10 years). This finding confirms a relatively low diet adherence in the former age group (Walter et al 2002).

The BodPod whole body air-displacement plethysmography method is a relatively new technique to measure body composition. It has shown to be an accurate system in comparison with more conventional methods of body composition measurement like hydrostatic weighing and dual energy X-ray absorptiometry (DEXA) (Fields et al 2002). Moreover, non-invasive evaluation of body composition in this manner is fast and safe, not only in adults but also especially in children above 6 years of age (Fields et al 2002).

In order to gain more insight into the body composition of children with PKU, we designed a study in which the BodPod system was used to analyse body composition in these patients.

\section{Patients and methods}

All patients diagnosed with PKU born between 1991 and 2001 and treated in our centre were included in this study. Patients had been identified by newborn screening and required dietary treatment for PHE level control. Diagnosis was confirmed by mutation analysis of the phenylalanine hydroxylase gene. Patients were treated from birth according to the Dutch PKU Guidelines, with a natural protein restricted diet and supplementation of PHE-free amino acids. The average protein intake was $1.3-1.5$ times above RDA. None of the children received $\mathrm{BH} 4$ supplementation. Children with hyperphenylalaninaemia requiring only minor dietary protein restriction without amino acid supplementation were excluded.

Body composition in patients with PKU was measured using the BodPod whole body air-displacement plethysmography method (Life Measurement Incorporation $(\mathcal{C}$; Fig. 1). After system warming-up, calibration and manual entering of gender, age and body height of the children, body weight was the first parameter to be determined by stepping on the BodPod weighing scale (Life Measurement Incorporation( 1 2004). Second, patients were seated within the BodPod chamber wearing tight underwear and a bathing cap, to minimize extracorporeal air volumes which could eventually bias the measurements (Life Measurement Incorporation $($ 2004). Next, body volume was measured indirectly by determining the pressure change caused by the volume of air displacement of the subject sitting inside the tightly closed chamber. The thoracic gas volume was determined by letting the child breathe through a tube connected within the BodPod, to correct for the air volume contained within the lungs during the measurement procedure (Life Measurement Incorporation` ${ }^{\circ}$ 2004). From body

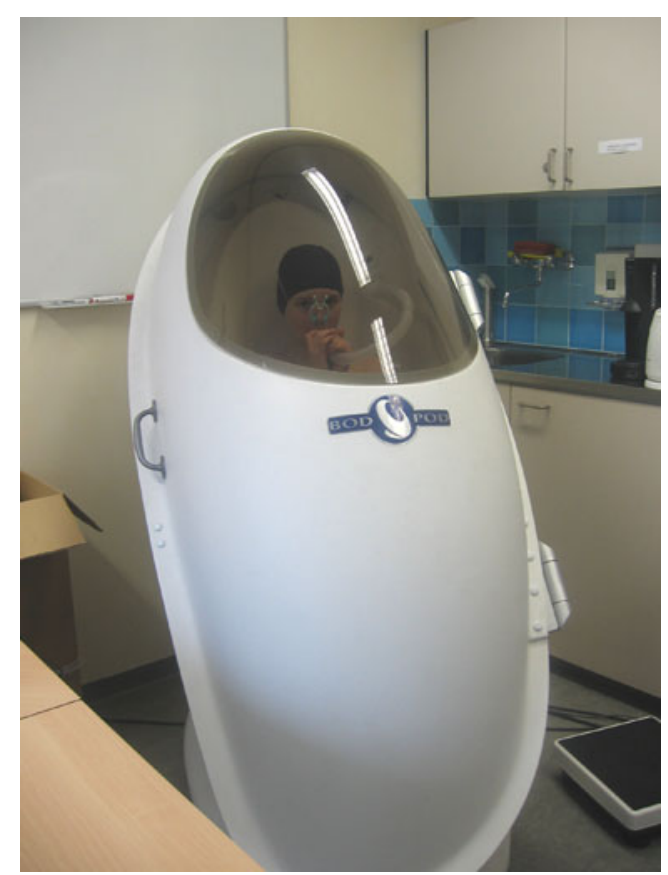

Fig. 1 A child within the BodPod whole body air-displacement plethysmograph 
mass and volume, and through body density, total fat mass, total fat free mass and the body fat percentage were calculated by the BodPod system (Life Measurement Incorporation(C) 2004). Total measurement time was approximately 4 minutes. Where lung volume measurements failed to succeed, average lung volumes were predicted by the BodPod system (Life Measurement Incorporation(C) 2004), and adjusted manually afterwards using specific formulas suitable for BodPod measurements in children (Fields et al 2004).

Each patient was matched for gender and age with one healthy control subject, of whom BodPod analysis data were derived from the Division of Human Nutrition at the Wageningen University and Research Centre, The Netherlands.

Blood PHE levels (in $\mu \mathrm{mol} / \mathrm{L}$ ) of patients with PKU were determined every 1-3 months in the year preceding BodPod measurements, using the High Pressure Liquid Chromatography-Tandem Mass Spectrometry (HPLC-MSMS) analysis method based on the procedure described by Chace et al (1993).

\section{Statistical analysis}

Subject characteristics were evaluated for accurate matching by calculating ranges and means as well as standard deviations of age, height and body weight of patients with PKU and their healthy control counterparts. In addition, the body mass index (BMI) was determined [weight $(\mathrm{kg}) / \mathrm{height}$ $\left.(\mathrm{m})^{2}\right]$. Median values were calculated when a parameter did not show normal distribution. Independent samples $t$ tests were applied to verify whether subject characteristics differed significantly between both groups.

Independent samples $t$ tests were used to test whether mean body fat percentages differed significantly between patients with PKU and healthy controls. In addition, because puberty changes body composition, subgroup analysis was performed for boys and girls $\leq 11$ years and $>11$ years of age. Based on previous repeated measurements in 18 healthy children in our laboratory (6-12 months apart), a power analysis demonstrated that with 20 subjects in each group, a $2.9 \%$ difference in body fat would be statistically significant (confidence level $\alpha$ of $5 \%$, power of $80 \%$ and a within-subject standard deviation of $3.4 \%$ body fat). Linear regression analysis was applied to study the association between body fat percentage and body weight in patients with PKU as well as in healthy control subjects.

In patients with $\mathrm{PKU}$, individual median values of monthly to quarterly blood PHE levels, determined within 1 year before BodPod measurements, were calculated. Mann-Whitney non-parametric analysis was applied to see whether mean blood PHE levels, calculated from individual median values, differed significantly among PKU patient subgroups. Linear regression analysis was performed to evaluate the correlation of blood PHE level with body fat percentage in these children.

The medical ethics committee of the Wageningen University and Research Centre, The Netherlands, has postulated that the study did not require their approval (06/17).

\section{Results}

Two out of 26 patients were excluded: one child with coexisting type I diabetes mellitus and one patient with coexisting severe attention deficit hyperactivity disorder. A total number of 24 children were subsequently invited, and both parents and children agreed to participate. In 4 children, body composition could not be measured due to anxiety and/or agitation. Analysis results were therefore available from 20 patients.

Both patients with PKU $(n=20)$ and healthy controls $(n=20)$ consisted of 7 boys and 13 girls. Median age in both groups was 10.0 years (Table 1). Children with PKU were comparable to their gender- and age-matched healthy counterparts with respect to height $(144.2 \pm 18.7 \mathrm{~cm}$ vs $150.7 \pm 14.1 \mathrm{~cm} ; 95 \%$ confidence interval (CI) -17.2 to $4.0 \mathrm{~cm})$, body weight $(41.2 \pm 16.7 \mathrm{~kg}$ vs $40.7 \pm 11.9 \mathrm{~kg}$; $95 \% \mathrm{CI}-8.8$ to $9.8 \mathrm{~kg})$ and BMI $\left(18.8 \pm 3.5 \mathrm{~kg} / \mathrm{m}^{2}\right.$ vs $17.5 \pm 2.0 \mathrm{~kg} / \mathrm{m}^{2} ; 95 \% \mathrm{CI}-0.5$ to $3.2 \mathrm{~kg} / \mathrm{m}^{2}$ ) (Table 1 ).

The mean body fat percentage was significantly higher in patients with PKU compared to healthy control subjects $(25.2 \pm 7.3 \%$ vs $18.4 \pm 5.8 \% ; p=0.002)$ (Fig. 2, Table 2$)$. This difference was most pronounced in girls $(24.8 \pm 8.2 \%$ vs $18.7 \pm 4.4 \% ; p=0.026)$ and especially above 11 years of age $(30.1 \pm 5.5 \%$ vs $21.5 \pm 2.2 \% ; p=0.027)$ (Table 2$)$. Furthermore, body fat percentage in patients with PKU increased with body weight $(R=0.693, p=0.001)$ (Fig. 3).

Table 1 Subject characteristics for both patients with PKU and healthy control subjects $(n=40)$

\begin{tabular}{llll}
\hline Subject characteristics & $\begin{array}{l}\text { PKU patients } \\
(n=20)^{\mathrm{a}}\end{array}$ & $\begin{array}{l}\text { Healthy controls } \\
(n=20)^{\mathrm{a}}\end{array}$ \\
\hline Age $^{\mathrm{b}}$ (years) & Range & $6-16$ & $7-16$ \\
& Median & 10.0 & 10.0 \\
Height $(\mathrm{cm})$ & Range & $114.0-175.1$ & $123.0-179.0$ \\
& Mean $\pm \mathrm{SD}$ & $144.2 \pm 18.7$ & $150.7 \pm 14.1$ \\
Weight $(\mathrm{kg})$ & Range & $18.5-76.2$ & $23.0-74.0$ \\
& Mean $\pm \mathrm{SD}$ & $41.2 \pm 16.7$ & $40.7 \pm 11.9$ \\
$\mathrm{BMI}\left(\mathrm{kg} / \mathrm{m}^{2}\right)$ & Range & $14.0-25.3$ & $14.2-23.1$ \\
& Mean $\pm \mathrm{SD}$ & $18.8 \pm 3.5$ & $17.5 \pm 2.0$
\end{tabular}

\footnotetext{
${ }^{\text {a }}$ In both groups $(n=20)$, gender was equally distributed ( 7 boys and 13 girls)

${ }^{\mathrm{b}}$ Age did not show a normal distribution; therefore only range and median are given
} 


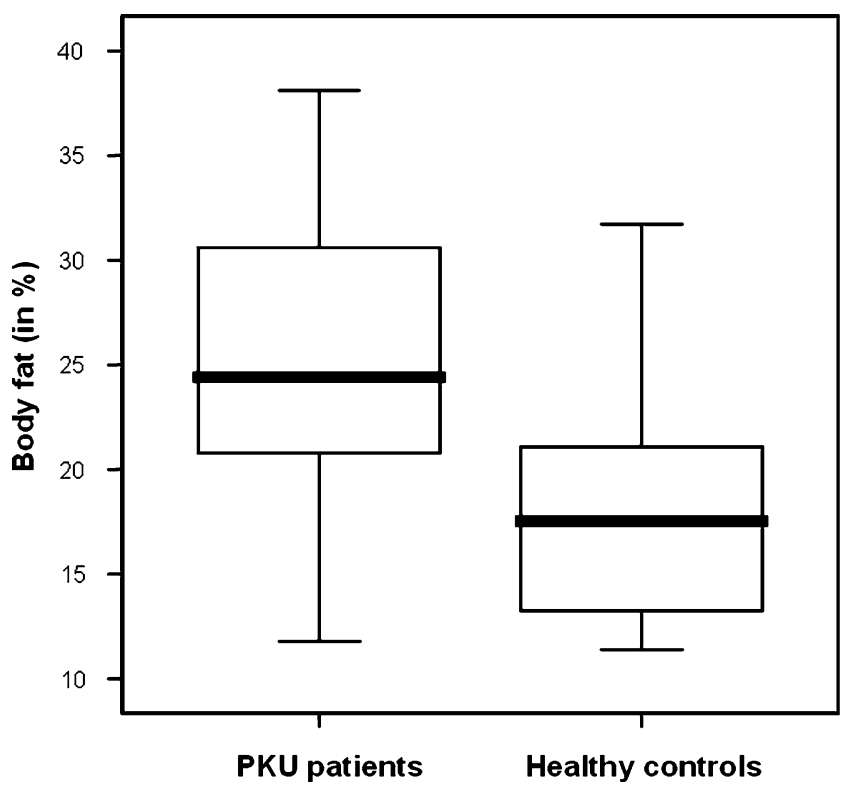

Fig. 2 Boxplot of body fat percentage in patients with PKU $(n=20)$ compared to healthy control subjects $(n=20)$

In the healthy control group, this increase was not observed ( $R=0.250, p=0.287$ ) (Fig. 3).

The mean blood PHE level in patients with PKU $(n=20)$, calculated from monthly to quarterly median individual values, was $375( \pm 253) \mu \mathrm{mol} / \mathrm{L}$ (Table 3$)$. Girls $(n=13)$ showed on average $129 \mu \mathrm{mol} / \mathrm{L}$ higher mean PHE level than boys $(n=7)(420 \pm 303 \mu \mathrm{mol} / \mathrm{L}$ vs $291 \pm 77 \mu \mathrm{mol} / \mathrm{L}$; Table 3$)$. This difference was even more pronounced above 11 years of age $[562 \pm 481 \mu \mathrm{mol} / \mathrm{L} \quad(n=4)$ vs $304 \pm 72 \mu \mathrm{mol} / \mathrm{L}(n=3)$; Table 3]. Mann-Whitney nonparametric analysis however, applied because PHE level did not have a normal distribution, showed that these PHE level differences between PKU patient subgroups were not significant (data not presented). After log-transformation of

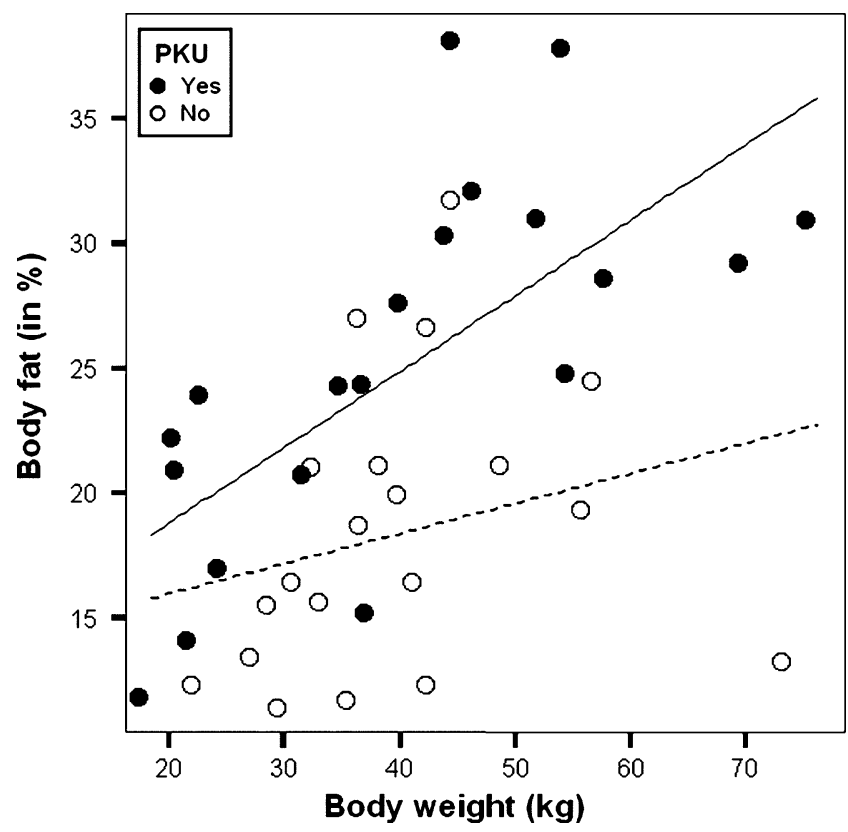

Fig. 3 Scatterplot with regression lines of body fat percentage against body weight in 20 patients with PKU ( $)(R=0.693, p=0.001)^{*}(-)$ and in 20 healthy control subjects $(\mathrm{G})(R=0.250, p=0.287)(-\cdots) . * p<0.05$

mean blood PHE level (to yield a normal distribution), linear regression analysis failed to show a correlation of PHE level with body fat percentage in patients with PKU $(R=0.079, p=0.740)$.

\section{Discussion}

Our data show that a higher body fat percentage is present in patients with PKU compared to healthy control subjects, especially in girls above 11 years of age. Our study furthermore confirms that the BodPod whole body air-

Table 2 Body fat percentage in patients with PKU compared to healthy control subjects $(n=40)$, with gender and age taken apart

\begin{tabular}{|c|c|c|c|c|c|}
\hline \multirow[t]{2}{*}{ Body fat (in \%) } & & \multicolumn{2}{|l|}{ Mean $+/-$ SD } & \multirow{2}{*}{$\begin{array}{l}\text { Significance }(p) \\
\text { of difference }\end{array}$} & \multirow{2}{*}{$\begin{array}{l}95 \% \text { Confidence interva } \\
(95 \% \mathrm{CI}) \text { of difference }\end{array}$} \\
\hline & & $\begin{array}{l}\text { PKU patients } \\
(n=20)\end{array}$ & $\begin{array}{l}\text { Healthy controls } \\
(n=20)\end{array}$ & & \\
\hline \multirow[t]{3}{*}{ All subjects $(n=40)$} & All ages & $25.2 \pm 7.3$ & $18.4 \pm 5.8$ & $0.002 *$ & $2.6-11.0$ \\
\hline & Age $\leq 11$ years $(n=26)$ & $24.1 \pm 7.6$ & $18.6 \pm 6.4$ & 0.056 & -0.1 to 11.2 \\
\hline & Age $>11$ years $(n=14)$ & $27.2 \pm 7.0$ & $18.2 \pm 4.6$ & $0.014 *$ & $2.1-16.0$ \\
\hline \multirow[t]{3}{*}{ Boys $(n=14)$} & All ages & $25.9 \pm 5.8$ & $17.9 \pm 8.1$ & 0.056 & -0.2 to 16.2 \\
\hline & Age $\leq 11$ years $(n=8)$ & $27.8 \pm 4.0$ & $21.1 \pm 9.8$ & 0.273 & -8.0 to 21.4 \\
\hline & Age $>11$ years $(n=6)$ & $23.4 \pm 7.9$ & $13.7 \pm 2.4$ & 0.113 & -3.6 to 22.8 \\
\hline \multirow[t]{3}{*}{ Girls $(n=26)$} & All ages & $24.8 \pm 8.2$ & $18.7 \pm 4.4$ & $0.026^{*}$ & $0.8-11.5$ \\
\hline & Age $\leq 11$ years $(n=18)$ & $22.5 \pm 8.4$ & $17.5 \pm 4.7$ & 0.135 & -1.8 to 11.8 \\
\hline & Age $>11$ years $(n=8)$ & $30.1 \pm 5.5$ & $21.5 \pm 2.2$ & $0.027^{*}$ & $1.4-15.9$ \\
\hline
\end{tabular}

$* p<0.05$ 
Table 3 Blood phenylalanine levels (in $\mu \mathrm{mol} / \mathrm{L}$ ) in PKU patients $(n=20)$, measured in the year preceding BodPod analysis, with gender and age taken apart

${ }^{\mathrm{a}}$ Mean Mean of median individual values

\begin{tabular}{llll}
\hline Patients with PKU & \multicolumn{2}{l}{ PHE level $(\mu \mathrm{mol} / \mathrm{L})$ mean $^{\mathrm{a}} \pm \mathrm{SD}$} & \\
\cline { 2 - 4 } & All patients & Boys & Girls \\
\hline All ages & $375 \pm 253(n=20)$ & $291 \pm 77(n=7)$ & $420 \pm 303(n=13)$ \\
Age $\leq 11$ years & $333 \pm 166(n=13)$ & $281 \pm 90(n=4)$ & $357 \pm 190(n=9)$ \\
Age $>11$ years & $451 \pm 369(n=7)$ & $304 \pm 72(n=3)$ & $562 \pm 481(n=4)$ \\
\hline
\end{tabular}

displacement plethysmography method is a convenient method to use in children with PKU.

In literature on PKU, results from weight and body composition studies are inconsistent. Whereas McBurnie et al (1991) reported a higher and above average weight in patients with PKU compared to healthy control subjects, Allen et al (1996) and Huemer et al (2007) found no significant differences in weight and body composition between these groups. Our data on the contrary show, within a population of only 20 patients with PKU and 20 healthy control subjects, a significant difference in body composition. Although BMI values are similar, a higher body fat percentage is present in children with PKU, especially in girls aged 11 years or older.

Since serum PHE values reflect dietary compliance particularly in older children (McBurnie et al 1991; Walter et al 2002), blood PHE levels in patients with PKU were evaluated. McBurnie et al (1991) showed a positive correlation of serum PHE values with body weight in children with PKU, and particularly in girls. We did not find an association between mean blood PHE level and body fat percentage in patients with PKU. Although girls above 11 years of age with PKU show mean PHE levels near the target level of $600 \mu \mathrm{mol} / \mathrm{L}$, standard deviations were remarkably large due to great inter-individual variations, and PKU subgroup sizes were relatively small, both of which explain our statistical analysis.

Singh et al (2009) show that the prevalence of overweight in Dutch adolescents (mean age 12.7 years) is higher in the case of non-Western origins (i.e. at least one parent born in Latin America, Africa, Turkey or Asia) compared to adolescents of Dutch descent. In the present study, although the numbers are very small, this phenomenon should also be taken into account. A total of 4 out of 20 patients with PKU (mean age 10.2 years) are from Turkish (3) and Latin American (1) descent, and 1 of them belongs to the subgroup with the highest body fat percentage (girls $\geq 11$ years of age). The healthy control subjects on the contrary are all of Dutch Caucasian descent. We therefore looked into the effect of exclusion of all 4 patients with PKU and a non-Western origin, along with their matched healthy counterparts, on body fat percentage. This did not change our conclusions.

The present study shows, within a group of only 20 children with PKU, a higher body fat percentage, especially in girls above 11 years of age. The BodPod whole body airdisplacement plethysmography method was found to be very suitable in this setting. Because the underlying aetiology of higher body fat percentages in patients with PKU compared to healthy control subjects cannot be clarified to date, further research is mandatory not only in prospect of elucidating disease and/or diet related changes in growth and body composition but also in relation to overall disease management strategies and outcome hallmarks. We therefore propose to regularly follow-up patients with PKU whenever a BodPod whole body airdisplacement plethysmography method is available.

Acknowledgement We would like to thank the Division of Human Nutrition at the Wageningen University and Research Centre for enabling us to make use of the BodPod whole body air-displacement plethysmograph.

Open Access This article is distributed under the terms of the Creative Commons Attribution Noncommercial License which permits any noncommercial use, distribution, and reproduction in any medium, provided the original author(s) and source are credited.

\section{References}

Acosta PB, Yannicelli S, Singh R et al (2003) Nutrient intakes and physical growth of children with phenylketonuria undergoing nutrition therapy. J Am Diet Assoc 103(9):1167-1173

Allen JR, Baur LA, Waters DL et al (1996) Body protein in prepubertal children with phenylketonuria. Eur J Clin Nutr 50 (3): 178-186

Arnold GL, Vladutiu CJ, Kirby RS, Blakely EM, DeLuca JM (2002) Protein insufficiency and linear growth restriction in phenylketonuria. J Pediatr 141(2):243-246

Blau N, Erlandsen H (2004) The metabolic and molecular bases of tetrahydrobiopterin-responsive phenylalanine hydroxylase deficiency. Mol Genet Metab 82:101-111

Chace DH, Millington DS, Terada N, Kahler SG, Roe CR, Hofman LF (1993) Rapid diagnosis of phenylketonuria by quantitative analysis for phenylalanine and tyrosine in neonatal blood spots by tandem mass spectrometry. Clin Chem 39:66-71

DeRoche K, Welsh M (2008) Twenty-five years of research on neurocognitive outcomes in early-treated phenylketonuria: intelligence and executive function. Dev Neuropsychol 33(4):474504

Dobbelaere D, Michaud L, Debrabander A et al (2003) Evaluation of nutritional status and pathophysiology of growth retardation in patients with phenylketonuria. J Inherit Metab Dis 26 (1): $1-11$ 
Fields DA, Goran MI, McCrory MA (2002) Body-composition assessment via air-displacement plethysmography in adults and children: a review. Am J Clin Nutr 75(3):453-467

Fields DA, Hull HR, Cheline AJ, Yao M, Higgins PB (2004) Child-specific thoracic gas volume prediction equations for air-displacement plethysmography. Obesity Research 12(11):1797-1804

Huemer M, Huemer C, Möslinger D, Huter D, Stöckler-Ipsiroglu S (2007) Growth and body composition in children with classical phenylketonuria: results in 34 patients and review of the literature. J Inherit Metab Dis 30(5):694-699

Life Measurement Incorporation $\left(\right.$ (2004) BodPod $^{\circledR}$ Body Composition Tracking System, Operator's Manual PN\#2102946 RevF, Concord, CA, USA

McBurnie MA, Kronmal RA, Schuett VE, Koch R, Azeng CG (1991) Physical growth of children treated for phenylketonuria. Ann Hum Biol 18(4):357-368
Singh AS, Chinapaw MJM, Brug J, Kremers SPJ, Visscher TLS, van Mechelen W (2009) Ethnic differences in BMI among Dutch adolescents: what is the role of screen-viewing, active commuting to school, and consumption of soft drinks and high-caloric snacks? Int J Behav Nutr Phys Act 6 (1):23. Correction: Int J Behav Nutr Phys Act 6(1):40

Verkerk PH, van Spronsen FJ, Smit GPA, Sengers RCA (1994) Impaired prenatal and postnatal growth in Dutch patients with phenylketonuria. Arch Dis Child 71:114-118

Walter JH, White FJ, Hall SK et al (2002) How practical are recommendations for dietary control in phenylketonuria? Lancet 360(9326):55-57

Walter JH, Lee PJ, Burgard P et al (2006) Hyperphenylalaninaemia. In: Fernandes J, Saudubray JM, Van den Berghe G, Walter JH (eds) Inborn metabolic diseases: diagnosis and treatment, 4th edn. Springer, Heidelberg, pp 221-231 